\title{
Assessment processes and principles related to Food Security that Zimbabwe can rely on for insight.
}

\author{
${ }^{1}$ Sifelani Ngwenya \\ ${ }^{1}$ Bulawayo, +263. Zimbabwe
}

\begin{abstract}
Increasing frequency and intensity of food insecurity in Zimbabwe, amidst heavy investment in Disaster Risk Reduction efforts threatens the achievement of the Zero Hunger target by 2030. The need to interrogate assessment practice need not to be overemphasized. An interpretive-constructivist paradigm guided this study, while desktop review, focus group discussions and individual interviews were the main data collection tools. A purposively selected sample, of 85participants from Bulilima, Gwanda, Mangwe, and Umzingwane districts was used. These districts share similar social and cultural characteristics and hazards. The sample consisted of District development coordinators (DDCs), Environmental Management Agency, Rural District Council (RDC) chief executive officers, councillors, traditional leaders (chiefs), NGO managers, and heads of schools, deemed to bring depth into the study. NVivo software was used in data analysis to establish order, structure, and meaning, to ensure coherence, consistency, and quality of research findings and deductions. The study found that the term, "assessment" was variedly understood across disciplines and levels of responsibility, due to the existence of parallel assessment regimes that fragment and weaken assessment practice. Hence, the need to make capacity-building, training and education and stakeholder participation a permanent feature in Zimbabwe. This will promote correct understanding and application of the terms, and increase the knowledge of DRR practice. Assessment practice challenges emanate from the manner in which stakeholders do assessments. Hence, the need for attitude change and commit to the pooling of all the resources towards the assessment practice, and adherence to standards and principles that govern assessment.
\end{abstract}

Keywords: Assessment; Disaster Risk Reduction; processes and principles; Food Security, stakeholders.

\section{Introduction}

The world continues to face increasing food insecurity, despite concerted efforts toward building national food securities. The increasing frequency and intensity of food insecurity in Zimbabwe threaten the efforts of achieving the Zero Hunger target by 2030. The continued support for development projects with no returns poses a heavy burden to national budgets, as the country struggles to maintain capital expenditure toward relief and rehabilitation. Thus, the need for assessment cannot be overemphasised, to better understand the impact of development projects on food security. The concept of assessment has evolved and developed across various domains to become a basic accountability requirement, an intricate social and technical fabric to judge project direction, progress and performance. Hence, the diversity of its methods (McDavid \& Hawthorn, 2006). Despite its mass recognition in the development arena and academia, the term assessment remains clouded by confusion (Baker, 2000; Sayce \& Norrish, 2006). Baker (2000) argues that very little is known about the actual influence of projects on the poor. Sayce \& Norrish, (2006) add that an assessment still presents a myth or at best an illusion to most development practitioners. Therefore, the confusion that clouds assessment contributes to the limited commitment and effort to assess the impact of projects on various communities. Despite, the criticisms, understanding the concept is a critical starting point in appreciating the events and phenomena that negatively impinge upon communities in various dimensions. It is against this background that this paper seeks to uncover stakeholders' conceptualization of assessment, its guiding principles, and its application thereof, which could contribute toward mutual efforts in solving food insecurity challenges in Zimbabwe and beyond. Therefore, informed largely by field-based 
evidence from four districts of Zimbabwe, namely Bulilima, Gwanda, Mangwe and Umzingwane, this paper attempts to point out issues that need to be considered in building up and maintaining a food insecurityresilient nation.

\section{Some theory behind assessment}

The term, assessment has been widely used across disciplines, such as development, education, engineering, medicine, among others (Melvin \& Garry, 2012). From the education perspective, assessment is the process of gathering evidence to make inferences on progress towards specific goals and shortcomings (Farell et al., 2002; Mingchu \& Leon, 2005). Meanwhile, Simonson (1997), Scriven (2007) and Kahan (2008) view assessment as an organised and systematic way of investigating or judging the merit, worth or significance of past and current initiatives/projects. However, Li., Klein., Balmer., \& Gusic (2020) define assessment as a systematic collection of information, about the activities, characteristics, and outcomes of a program, to understand their significance to stakeholders, for learning purposes. Therefore, assessment refers to a systematic way of gathering evidence or information by stakeholders, to judge or understand the significance of a project in order to draw lessons to future programming. Stakeholders are individuals or groups of people affected by a project or programme (Sterling et al., 2017). In the context of this study, the stakeholders are the Government of Zimbabwe departments, beneficiaries, non-beneficiaries, donors, NonGovernmental Organisations (NGOs) and traditional leaders. Assessments are done to investigate the effects of an intervention (Bamberger et al., 2012). Thus, they provide stakeholders with the platform to learn from experience, ensure accountability, transparency, deepen understanding, improve communication and learning to improve development outcomes (Austrian Development Agency, 2008; LeClair, 2015; United States Agency for International Development (USAID, 2016). Therefore, assessment should provide stakeholders with effective and innovative platforms to view, develop, regulate, formulate, predict and differentiate various outcomes, as guided by the principles and standards for assessment.

\section{Guiding principles and standards for assessment}

The assessment practice is guided by various principles and standards. Some of these principles and standards are objectivity, the independence of evaluators, the participation of all parties concerned, transparency, reliability, completeness and clarity of reports, utility, feasibility, propriety and accuracy (Austrian Development Agency, 2008, Yarbrough, 2017). These principles and standards ensure the assessment practice's compliance with standards and requirements for assessment Organization for Economic Cooperation and Development (OECD, 2007). Derbinski \& Reinhardt, 2017) advocate for the structuring of the assessment process to achieve high-quality assessments. First, utility ensures that an evaluation serves the information needs of intended stakeholders (JCSEE, 1994). Meanwhile, feasibility denotes a state of being feasible, ensuring that an assessment is realistic, prudent, diplomatic and frugal (ERIC, 1995; Your Dictionary, 2018). Conversely, propriety ensures that an evaluation is conducted legally, ethically, and with due regard for the welfare of all stakeholders (JCSEE, 1994), while accuracy ensures that an evaluation reveals and conveys technically adequate information about the features that determine the merit of the programme being evaluated (ERIC, 1995:4). Clarity refers to a quality or condition of being clear (Webster's New World College Dictionary, 2014), whereas credibility denotes being believed or relied upon or that is worthy of confidence (Webster's New World Law Dictionary, 2010), of having the power to elicit belief (The American Heritage, 2016). Last but not least, independence is the state or quality of being free from the influence or control of another or others (Webster's New World College Dictionary, 2014). Drawing from the above reflections, principles and standards of assessment give it a systematic flair for addressing evaluation questions, justifying conclusions, and avoiding or minimising distortion and bias for evaluating a programme. As a result, non-compliance with evaluation standards discredits the assessment practice. Ahmed et al. (1999) and Baker (2000) advance that comprehensive and effective evaluation programmes should embrace the monitoring process, cost-benefit analysis, and impact evaluation assessment at all stages of the project continuum. The effectiveness of an evaluation is enhanced by extracting information and establishing links from past, present and future interventions (United Nations Development Programme (UNDP, 2002). Hence, the importance of assessment in linking the past and present to generate future programmes. However, the principles upon which the assessment practice is built cannot guarantee the success of all-stakeholder assessment, hence the need for strong political commitment, stakeholder engagement and resilience. 
Stern et al (2012) explain that credible assessment addresses four generic questions to measure different aspects of the cause and effect. These questions are: To what extent can a specific (net) impact be attributed to the intervention? Did the intervention make a difference? How has the intervention made a difference? and, Will the intervention work elsewhere? Impact denotes any short-term or long-term tangible and intangible effect of the service, event or initiative on an individual or group, or on an entity's actions (FitzGibbon, 1996; Streatfield \& Markless, 2010; OECD, 2010). In the context of this study, impact denote the observable results of a project. For example, increased access to clean water, an increase in the number of nutritious meals, or a decline in malnutrition cases in a given community to mention but a few. Therefore, the impact is an identifiable positive or negative intended or unintended result of an initiative. This study seeks to understand various stakeholders' conceptualization of the assessment construct, its guiding principles, and its application theory, on implemented projects. in the assessment. Such findings could positively contribute toward mutual Disaster Risk Reduction (DRR) efforts that can solve food insecurity challenges in Zimbabwe and beyond.

\section{Research purpose and questions}

This research is based on the researchers' involvement and experiences in DRR initiatives in Bulilima, Gwanda, Mangwe, and Umzingwane districts in southern Zimbabwe during 2006-2020. It was during these interactions with stakeholders of the four districts that issues around the concepts assessment, practices and principles emerged. Stemming from these interactions, the research set out to find out the out issues that need to be considered in building up and maintaining a food insecurity-resilient nation. The guiding questions of this study were the following:

1. What are the stakeholders' understanding of the concepts of assessment, principles and processes?

2. To what extent are stakeholders able to do assessment in accordance to practices and principles that guide assessment?

3. How do assessment principles and practices link with Disaster Risk Reduction initiatives?

4. What challenges do stakeholders face in the process of assessing implemented community projects aimed at reducing the risk of disasters?

As these questions sought to solicit unquantifiable responses, opinions and experiences, a qualitative approach became the approach of choice.

\section{MATERIALS AND METHODS}

An interpretive-constructivist paradigm was used to guide the study. As such, qualitative data were collected to understand the phenomenon, "assessment" in food security-related Disaster Risk Reduction initiatives. The design adopted by the study offers a systematic and subjective way that describes the life and give meaning to human experiences (Patel and Patel, 2019). Hence, its suitability in enhancing the understanding of social or human problems, particularly those linked to the assessment of DRR initiatives, working towards enhancing food security. Thus, appropriate data collection methods consistent with qualitative research such as desktop review, focus group discussions and individual interviews were used to collect data from a purposively selected sample, of 85 participants in Bulilima, Gwanda, Mangwe, and Umzingwane districts. The adopted data collection methods enabled the researcher to triangulate the data and hence ensuring the trustworthiness of the findings. The sample of the study was deemed appropriate and sufficient for the Central Limit Theorem (CLT) to hold (Ganti, 2021). The study area was selected for sharing similar characteristics with respect to social and cultural aspects, and their susceptibility to hazards (Ngwenya, 2021). The study participants included district development coordinators (DDCs), Environmental Management Agency, Rural District Council (RDC) chief executive officers, councillors, traditional leaders (chiefs), NGO managers, and heads of schools. These participants were pivotal to this research for the depth they brought into the study. These participants had decision-making, institutional gate keepership, and custodianship of communities, knowledge and technical expertise, and experience in the implementation of development projects. Participants were granted an opportunity to express their views freely about the assessment, practices, and processes in relation to DRR initiatives working towards ensuring food security. As such, interviews were conducted in vernacular language, to enable the researchers 
to access participants' feelings, intentions, perceptions, beliefs, knowledge, and opinions. Data were analysed using NVivo software, to establish order, structure, and meaning to present it in a systematic manner (Archer, 2018). This process ensured a coherent, consistent, holistic, and quality-focused approach that advances constructive research findings and deductions (Ngwenya, 2021). The purpose of the study was explained to stakeholders, the confidentiality of their information assured, and that it was to be used solely for educational purposes.

\section{Results And Discussion}

\section{Conceptualisation of sustainable livelihood assessments}

Interrogating participants' conceptualisation of the term, helped distinguish and categorise their basic understanding and test uniformity levels to inform the study. The study found assessment to be a common exercise amongst participants in four districts, with sixty-six per cent (66\%) claiming to have partaken in the exercise, while 34\% could neither confirm nor deny participation. Empirical findings indicate that people's understanding of livelihood assessment varies across disciplines and levels of responsibility. The chiefs, councillors and headmasters viewed assessment as analysis and diagnosis of community needs, livelihoods, food aid challenges and involvement of leaders. Their perceptions and diction indicate the frequency of their interaction and involvement in projects in their communities. Equally, Agritex, DDC, EMA, HM and RDC CEOs viewed assessment as analysis and diagnosis of opportunities, potential, preparedness levels, utilisation of locally available livelihoods, viability levels and needs of future generations. One EMA officer had this to say:

"assessment is an analysis done to check the livelihood programme's ability to meet the future needs of generations and also checking livelihood options that are available and their ability to assist in the long run" (Interviewee 38).

This view resonates well with the thematic issue of sustainability, which emphasises the aspect of meeting the needs of the present without compromising the ability of future generations to meet their needs (Investopedia, 2020). Participants agreed that assessment entails analysis and diagnosis. Hence, its consonance with the definitions by Chambers et al. (1981:1), the Austrian Development Agency (2008:4), Bamberger (2012:2) and Elizondo (2015:4), "a systematic and empirical investigation of the effects of an intervention on a system or entity's (livelihoods) resource productivity on a long-term basis". The study found government functionaries displaying a good grasp of interpretation and understanding of the concepts. This could be attributed to their many years of practice, experience and higher educational qualifications in the field of Disaster Risk Reduction. Furthermore, the study found varied views on the purposes of assessments. These range from to: get a full picture of food insecurity, determine support level, gather information, identify gaps that exist in livelihoods, assess the impact, and identify vulnerable groups. The purpose given is inconsistent with those propounded by White (2009:3), Terrell (2012:258) and Brown (2012:4), "to identify the actual outcomes of a programme, to explore the how and why of the programme outcomes and to bring an understanding of the success or failure and provide direction for programme improvement". Therefore, the lack of uniformity in understanding the purpose of assessments indicates the need to make capacity-building, training and education and stakeholder participation a permanent feature in Zimbabwe. This could promote a correct understanding and application of the terms, and commitment to the assessment practice, thereby significantly contributing to the expansion of the multi-sectoral knowledge of the DRR practice.

\section{Assessment practices and processes}

The study found that food security related assessment processes in Zimbabwe are guided by the national assessment report (Zimbabwe Vulnerability Assessment (ZimVAC). One female FGD participant in Umzingwane district had this to say:

"We hold meetings; trainings and workshops; formation of projects committees; delegation of duties; monitoring of partners, partners bring their own assessment equipment (that is, questionnaires, etc.) projects. Finally, we do the assessment by the district monitoring team"

This view was adopted as the district's view. However, Bulilima district added that baseline surveys precede the implementation of any project to inform the district on strengths, weaknesses, opportunities and threats 
that can present. Gwanda district, affirmed the questionnaire as the mainstay assessment tool, while NGOs conveyed that they engage external consultants to expedite the assessment process.

\section{Practice of outsourcing consultancy services}

Fifty-three per cent $(53 \%)$ of the participants were of the view that outsourcing consultants remain a necessary practice in disaster risk assessment, because they bring depth, new knowledge and innovations into the assessment practice. In support of this view, one DDC said:

"The consultants bring new knowledge and new experience that can be used for planning purposes.". In the same vein, the chiefs, DDC and school headmasters echoed that consultants had the technical expertise to guide assessment. Meanwhile, NGOs enunciated that they engage consultants to avoid conflict of interest, to get an independent opinion or view on the settings, to interrogate the organisation's strategies, triangulate information, get genuine information that informs the organisation planning and programming. The study found that NGOs outsource consultants because they are well resourced and equipped to offer guidance, based on their expertise and vast experience in the assessment field. Therefore, outsourcing consultants can help change management's focus, guard against self-interest, and enhance transparency and accountability. However, forty-seven per cent (47\%) viewed consultancy outsourcing as nonessential, in that it is a mere wastage of resources, inhibits professional growth of employees, exposes the organisations to unacceptable practices and external customs and that they are too detached from communities and not independent. Furthermore, NGOs further expressed that consultants come with costs, have a bias towards their employer, suffer the temptation of copying and pasting results of similar projects. The inference is that consultants, lack total independence, expose the district to unacceptable practices, the disempowerment of locals, deprive them of opportunities to practise and grow professionally and limits regular participation and feedback. Hence, its contradiction of principles and practices of inclusivity and engagement, which are the crux of Sustainable Livelihood initiatives. Having reviewed the consultancy outsourcing debate, it becomes paramount to review an entity's capacity to carry out assessments

\section{Capacity to carry out assessments.}

Empirical findings indicate that $38 \%$ of the participants had the capacity to carry out assessments, while $44 \%$ had the little capacity and $18 \%$ had none. These findings indicate limited or weakened capacities of most stakeholders in the districts and strengthen capacities on the part of NGOs. During interviews with the DDCs, headmasters, councillors and Agritex, there was unanimity on capacitation in terms of human resources and Indigenous Knowledge (IK) in the four districts. Figure 1. summarises the views of participants on their capacity to carry assessments.

\section{Capacity to carry out assessments}

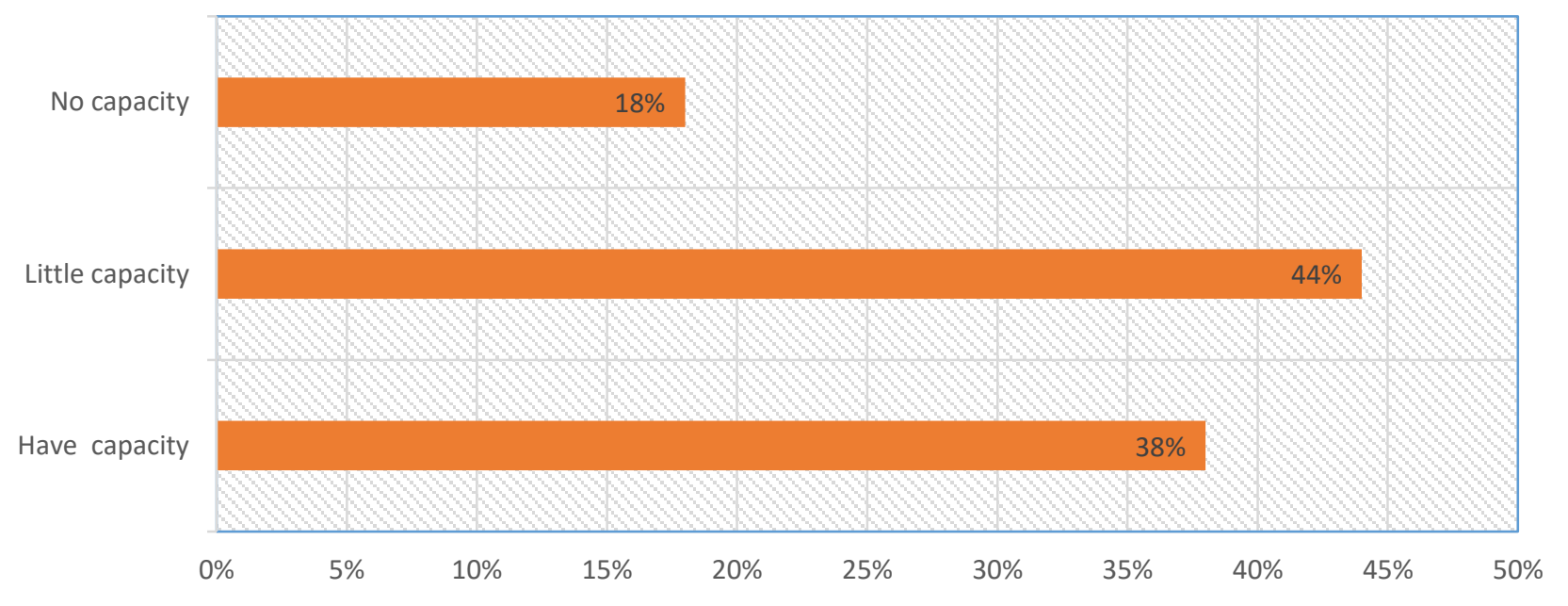

Figure 1: Capacity to carry out assessments 
Drawing from the Figure 1 findings and discussions, district capacitation is skewed towards human resources. Hence, their incapacitation in other areas, which thwart their assessments processes. One male EMA officer observed: "Financial resources are always limiting for assessments to be carried out regularly and also for monitoring to be done on implementation of plans." Therefore, financial resources limit districts' capacities to acquire the necessary resources to effectively carry out project assessments. In this regard, limited resources are indicative of a limited or lack of stakeholder support and commitment to the assessment agenda. Contrary, to the views of limited or no capacitation expressed by other stakeholders, NGOs are capacitated in every aspect, namely: the right expertise and experience, vehicles, gadgets and funding. Therefore, the above exposition attests to the existence of parallel assessment regimes that fragment and weaken assessment practice in all districts. This disintegrated approach defeats the whole purpose assessment and is in direct contradiction with the principles of inclusivity, participation and reliability. The next section scrutinises the participants' perceptions of the assessment practice.

\section{Perceptions around the assessment practice}

The findings were that, in practice, assessments are done to analyse various needs, to get information to inform the present and future plans. The other finding was that political commitment levels to the assigned practices determine the resource allocation support levels, to function effectively and efficiently. First, the apprehension of assessment by participants across the various districts covers a scattered range from disagreeing to strongly agree. In the light of the theoretic underpinnings clarified there is strong support for the proactive implementation of Livelihood assessments. About 83 per cent (83\%) of participants strongly agree that assessment is a systematic way of gathering project evidence and significance to learn and improve delivery. As such, 67 per cent, agreed that assessments are only done to comply with donor and legislative requirements. Meanwhile, 50 per cent of participants viewed assessments as a proactive DR mechanism and as a means to respond to/disaster situations. However, the only concern was that assessments are driven by the need to comply with the donor and the legislative requirements. As such, the assessments' commitment, true value and outcomes may be questionable. This is in direct contradiction with assessment standards and principles, for example, objectivity and independence (JCSEE, 1994: 63 and ERIC, 1995:2). Therefore, assessments that are not done in line with assessment standards and principles, suffer compromised credibility. The following section reviews assessment's linkages with DRR.

\section{Assessment-disaster risk reduction linkages}

Empirical findings of the study indicate that $90 \%$ of the participants believed that assessments are heavily linked with DRR, in that they can help to lower risks of disasters happening, while $10 \%$ disagreed. Those in disagreement argued that assessments lack credibility because they use people who have been overresearched. Meanwhile, those in support of assessment opined that they provide early warning information, broaden prevention awareness, shed light on successes and failures, guide future preparedness and mitigation plans, which resonate well with DRR. One RDC CEO in Mangwe had this to say:

\section{"By doing assessment you are able to identify issues early and take preventative measures to avert disasters".}

Furthermore, the proponents of assessments credited the practice for providing stakeholders with platforms to share relevant experiences/ findings, stimulating information gathering for correct and applicable decisions. Therefore, the ability of the assessments as a management tool to inform future programming, preparedness planning strongly link it with disaster risk reduction. Hence, its relevance of assessment practice to the DRR matrix. Drawing from the arguments for assessment, there is a high likelihood for communities to maintain the practice because of what it contributes to DRR. To further enhance the appreciation of the assessment practice, it becomes paramount to focus on assessment-related challenges.

\section{Assessment-related challenges}

The study found that the assessment practice in the four districts is negatively impacted by various challenges. Table 1 presents the assessment-related challenges as identified by focus groups. 
Table 1: Assessment-related challenges

\begin{tabular}{|l|l|l|l|l|}
\hline Challenges by district & Bulilima & \multicolumn{1}{|l|}{ Gwanda } & Mangwe & Umzingwane \\
\hline Creating identity crises & - & $\mathrm{X}$ & - & - \\
\hline $\begin{array}{l}\text { Failure to see the importance } \\
\text { of assessments }\end{array}$ & $\mathrm{X}$ & - & - & - \\
\hline Falsification of data & $\mathrm{X}$ & - & $\mathrm{X}$ & - \\
\hline Incapacitation (resources) & & $\mathrm{X}$ & $\mathrm{X}$ & $\mathrm{X}$ \\
\hline $\begin{array}{l}\text { Lack of locally generated } \\
\text { assessment tools }\end{array}$ & $\mathrm{X}$ & - & - & - \\
\hline $\begin{array}{l}\text { lack of commitment by } \\
\text { stakeholders }\end{array}$ & & & $\mathrm{X}$ & \\
\hline $\begin{array}{l}\text { Lack of feedback amongst } \\
\text { stakeholders }\end{array}$ & $\mathrm{X}$ & - & $\mathrm{X}$ & - \\
\hline $\begin{array}{l}\text { Our tools suffer copy and } \\
\text { paste syndrome }\end{array}$ & $\mathrm{X}$ & - & - & - \\
\hline $\begin{array}{l}\text { Poor mobile network } \\
\text { coverage }\end{array}$ & - & $\mathrm{X}$ & & $\mathrm{X}$ \\
\hline $\begin{array}{l}\text { Poor platform for } \\
\text { information dissemination }\end{array}$ & - & - & $\mathrm{X}$ & - \\
\hline $\begin{array}{l}\text { Staff turnover and staff } \\
\text { mobility }\end{array}$ & - & - & - & $\mathrm{X}$ \\
\hline $\begin{array}{l}\text { Misunderstanding } \\
\text { assessment tools }\end{array}$ & $\mathrm{X}$ & - & - & - \\
\hline $\begin{array}{l}\text { Uncoordinated development } \\
\text { partners }\end{array}$ & - & $\mathrm{X}$ & - & - \\
\hline
\end{tabular}

The challenges bear reference to incapacitation due to limited resources and support in terms of funding, lack of resources and inadequate logistics, lack of a standardised feedback platform. The challenge of poor mobile network coverage is most prevalent in Gwanda and Umzingwane districts, while the challenge of uncoordinated development partners is prevalent in Gwanda districts. Falsification of data was raised in the Bulilima and Mangwe districts, while, lack of locally generated assessment tools was highlighted in the Bulilima district. Staff mobility and turnover was recorded in Umzingwane district, while the lack of commitment by stakeholders was observed in Mangwe district. Participants in the Bulilima district indicated that assessments tools are likely to be misunderstood, resulting in the collection of wrong and irrelevant data. Thus, if these challenges are not addressed most projects are likely to fail. The assumption is that the identified overarching assessment challenges emanate from the lack of political will and commitment, inclusivity and duplication of effort. This scenario portrays a relaxed attitude vis-à-vis the assessment practice, its principles and standards. Consequently, this relaxed attitude thwarts inclusive participation, brings disharmony to the assessment approach, results in the duplication of effort and fruitless expenditure of donor and state funds. Hence, the need for an all-inclusive assessment framework FS related projects that will help address these challenges

\section{Conclusions}

It is apparent from the discussions that took place in Bulilima, Gwanda, Mangwe and Umzingwane that, "assessment" remains a popular term and exercise that has not been fully utilised to realise the benefit that comes along with it. More so, assessment is variedly understood transdisciplinary and in terms of responsibility levels. The level and degree of the assessment practice's comprehension determines the value attached to it, stakeholder commitment levels, and approach to its process and its results. Despite it's the term's popularity and value amongst various stakeholders, assessment continues to be overlooked, accorded little priority, and done in an ad hoc manner and on an individual basis. Furthermore, no policy document or 
universal assessment framework to guide stakeholders exists. Therefore, this ad hoc and individualistic approach indicate philosophical short-sightedness on the benefits of assessment, such as ensuring accountability, transparency, and efficiency, among other things. The challenges that bedevil the assessment practice emanates from lack of political will and commitment, exclusion and duplication of effort. Some of the challenges bear reference to disjointed assessment activities, incapacitation, lack of commitment, and lack of locally generated assessment tools among others. In consequence, this laxity attitude thwarts inclusive participation, brings disharmony to the assessment practice, resulting in the duplication of effort. Hence, the need for an all-inclusive assessment framework FS related projects that will help address these challenges

Based on the articulated findings, and conclusions, the study recommends the establishment of a political mechanism to remove obstacles to inclusionary and participative planning. There is also a need for stakeholders working in DRR issues to modify their assessment policies and practices to guide assessments transdisciplinary. Furthermore, the study recommends, strategic lobbying for stakeholder commitment toward sustainable livelihood assessment (through the mobilization of political systems and institutions, to adopt policies and allocate resources and coordination of responses for as long as necessary to ensure results). Therefore, taking this route may be critical in addressing incapacitation challenges. Another recommendation is canvassing for support to build and sustain the capacity of all stakeholders. The study further recommends the development of cooperation and networking platforms amongst various sectors and stakeholders as a way of fostering new partnerships to encourage the ethic of working together and participation. More so, all stakeholders should adopt a radical shift from an ad hoc approach to a proactive approach towards the assessment agenda. This can be achieved when all stakeholders adopt and adapt their actions and convictions to the guiding standards and principles of assessment, programme improvement, commitment, providing direction for improvement, provision of clear insight and evaluation of claims, knowledge generation to inform learning. In turn, this radical shift will foster confidence, participatory equity, accountability, transparency, partnerships and networks, a sense of programme ownership and trust among different stakeholders. Furthermore, this shift can bring about change in the stakeholder's mind-set that will help improve the assessment practice, contributing to new and beneficial innovations. It is hoped that this research will help facilitate all stakeholder inclusion in assessment policy-making processes and practice.

\section{Ethics approval and consent to participate}

Ethical clearance was obtained from the Ethics Committee FNAS North West University with number: NWU-01665-20-A9

\section{List of abbreviations}

$\begin{array}{ll}\text { CEO } & : \text { Chief Executive officers } \\ \text { CLT } & : \text { Central Limit Theorem } \\ \text { DDCs } & : \text { District Development Coordinators } \\ \text { DRR } & : \text { Disaster Risk Reduction } \\ \text { EMA } & : \text { Environmental Management Agency } \\ \text { ERIC } & : \text { Educational Resources Information Centre } \\ \text { FGDs } & : \text { Focus Group Discussions } \\ \text { HM } & : \text { Headmaster } \\ \text { IK } & : \text { Indigenous Knowledge } \\ \text { JCSEE } & : \text { Joint Committee on Standards for Educational Evaluations } \\ \text { NGO } & : \text { Non-Governmental Organisations } \\ \text { OECD } & : \text { Organization for Economic Cooperation and Development } \\ \text { RDC } & : \text { United Nations Development Programme } \\ \text { UNDP } & : \text { United States Agency for International Development } \\ \text { USAID } & : \text { Zimbabwe Vulnerability Assessment Committee } \\ \text { ZIMVAC } & \end{array}$




\section{Data Availability}

This study was carried out based on qualitative data collected from four district of Zimbabwe. If needed, the data are available from the corresponding author, S.N., upon reasonable request

\section{Conflicts of Interest}

No potential conflict of interest was reported by the authors

Funding Statement

This study was supported financially partly by the North-West University in South Africa bursaries, the post-graduate tuition and post-graduate international students.

\section{Authors' contributions}

S.N. worked on the idea formulation; designed the theoretical framework, methodology, data collection and analysis; and wrote the article.

\section{Acknowledgments}

This article is partially based on the author's thesis for the degree Doctor of Philosophy in Science with Disaster Risk Science at the North-West University in South Africa, with promoter Prof ES van Eeden and co-promoter Dr. W Lunga, submitted in December 2020.

\section{Supplementary Materials None}

\section{References}

1. A. Brown, 2012. CDC Coffee break: Using mixed methods program evaluation. https://www.cdc.gov/dhdsp/pubs/docs/cb_july_2012pdf Date of access:30 Jan.2021.

2. A. Ganti, 2021. Central Limit Theorem (CLT). [web log post] Retrieved from: https://www.investopedia.com/terms/c/central_limit.

3. American heritage dictionary of the English Language. 2016. 5th ed. Houghton Mifflin Harcourt Publishing Company.

4. Austrian Development Agency, 2008. Guidelines for project and programme evaluations. Vienna: Austrian Development Agency, Evaluation Unit.

5. B. Kahan, \& K. Consulting. 2008. Excerpts from review of evaluation frameworks. Regina: Saskatchewan Ministry of Education.

6. C.T. Fitz-Gibbon, L.L \& Morris, Theory-based evaluation," Evaluation Practice, vol.17 no.2pp.177184, 1996.

7. D. LeClair, 2015. The evolution of assessment and its forces of change. https://www.aacsb.edu/blog/2015/september/revolution-of-assessment-and-its-forces-of-change. Date of access:19 Jun. 2021.

8. D. Streatfield and S. Markless. 2010. What is impact assessment and why is it important. In Qualitative and quantitative methods in libraries: Theory and Applications (pp. 349-356).

9. D.B. Yarbrough, "Developing the program evaluation utility standards: Scholarly foundations and collaborative processes," Canadian Journal of Program Evaluation, vol. 31no.3, 2021

10. E. J. Sterling, E. Betley, A. Sigouin, A. Gomez, A.Toomey, G. Cullman, C. Malone, A. Pekor, F. Arengo, M.Blair, and C. Filardi, "Assessing the evidence for stakeholder engagement in biodiversity conservation," Biological conservation, vol. 209, pp.159-171, 2017.

11. E. Stern, N. Stame, J. Mayne, K. Forss, R. Davies, and B. Befani. 2012. Broadening the range of designs and methods for impact evaluations: Report of a study commissioned by the Department for International Development. London: DFID.

12. ERIC (Educational Resources Information Centre). 1995. The Program Evaluation Standards. ERIC/AE Digest. Washington, DC: ERIC Clearinghouse on Assessment and Evaluation.

13. H. White, "Theory-based impact evaluation: principles and practice," Journal of development effectiveness, vol.1, no.3, pp.271-284, 2009.

14. H.M.G. Elizondo, 2015. Mining and resource mobilization for social development: the case of Nicaragua. UNRISD working paper 2015-9. Geneva: United Nations Research Institute for Social Development (UNRISD). 
15. I.I Ahmed and M. Lipton, 1999. Impact of structural adjustment on sustainable rural livelihoods: a review of the literature. IDS Working Paper 62. Sussex: Institute for Development Studies.

16. Investopedia. 2019. Population Definition https://www.investopedia.com/terms/p/population.asp Date of access: 17 Jan. 2021.

17. J.C, McDavid and L.R.L Hawthorn. 2006. Program evaluation and performance measurement: an introduction to practice. Thousand Oaks: SAGE Publications.

18. J.L. Baker. 2000. Evaluating the impact of development projects on poverty. A handbook for practitioners. Washington, D.C: The World Bank.

19. JCSEE (Joint Committee on Standards for Educational Evaluation). 1994. The program evaluation standards 2nd ed. Thousand Oaks, CA: Sage.

20. K. Sayce and Norrish, P. 2006. Perceptions and practice: an anthology of impact assessment experiences. Technical Centre for Agricultural and Rural Cooperation.

21. K.Farell, M. Kratzmann, S. McWilliam, N. Robinson, S, Saunders, J. Ticknor, \& K.White, 2002. Evaluation made very easy, accessible, and logical. Nova Scotia: Atlantic Centre of Excellence for Women's Health.

22. L. Mingchu and D. Lion, "Mixed methods design for an objective - based evaluation of a magnet school assistance project," Evaluation and Program Planning, vol. 28, pp.109 -118, 2005.

23. M. Scriven. 1991. Evaluation Thesaurus, 4th edi. Newbury Park, CA: Sage.

24. M. Bamberger, J, Rugh \& L. Mabry, 2012. Real world evaluation. 2nd ed. Thousand Oaks: Sage Publications.

25. M. Melvin and T. H Gary, "Logic models and content analyses for the explication of evaluation theories: The case of emergent realist evaluation," Evaluation and Program Planning, 38(2013):74-76, 2012.

26. M. Patel and N. Patel, "Exploring Research Methodology: Review Article," International Journal of Research and Review, vol.6, no.3, pp. 48-55, 2019.

27. M. Scriven, M. 2007. Key Evaluation Checklist, Evaluation Checklists Project. University of Michigan.

28. M.R. Simonson, "Evaluating teaching and learning at a distance," New Directions for Teaching and Learning, vol. 71, pp.87-94, 1997

29. N. Derbinski \& T. Reinhardt, 2017. The Evaluation process in 10 steps - a guideline. Berlin: Brot für die Welt -Evangelischer Entwicklungsdienst Evangelisches Werk für Diakonie und Entwicklung e. V.

30. OECD (Organisation for Economic Cooperation and Development). 2007. Annual report Paris: OECD www.oecd.org. Date of access:26 Sep. 2021.

31. OECD (Organization for Economic Cooperation and Development). 2010. Evaluating development cooperation: Summary of key norms and standards. Paris: OECD. http://www.oecd.org/dataoecd/12/56/41612905.pdf Date of access: 16 May. 2021

32. R. Chambers, R. Longhurst \& A. Pacey, eds. 1981. Seasonal dimensions to rural poverty (pp. 231233). London: F. Pinter.

33. S. Ngwenya, "Reflecting on Early 21st Century Sustainable Livelihood Projects towards Enhancing Food Security and Resilience in Zimbabwe," International Journal of Research and Innovation in Applied Science vol. 6, no.10, pp. 35-42, 2021. https://dx.doi.org/1Q.51584/IJRIAS.2021.

34. S.R. Terrell, "Mixed-methods research methodologies," The qualitative report, vol. 17, no.1. pp.254280, 2012. https://nsuworks.nova.edu/tqr/vol17/iss1/14 Date of access: 21 Sep. 2021.

35. S.T.T. Li, M. D. Klein, D.F.Balmer, and M.E, Gusic, 2020. Scholarly evaluation of curricula and educational programs: using a systematic approach to produce publishable scholarship. Academic Pediatrics.

36. UNDP (United Nations Development Programme). 2002. Handbook on monitoring and evaluating for results. New York, NY: UNDP.

37. USAID (United States Agency for International Development). 2016. Maize production and marketing in Zimbabwe: policies for a high growth strategy. USAID strategic economic research and analysis. Zimbabwe (sera) program, Nathan Associates Inc.

38. Webster's New World College Dictionary. 2014. Fifth Edition Copyright (C) 2014 by Houghton Mifflin Harcourt Publishing Company. 
39. Webster's New World Law Dictionary. 2010. Wiley Publishing, Inc., Hoboken, New Jersey. https://www.yourdictionary.com/credibility Date of access: 13 Feb. 2021.

40. Your Dictionary. 2018. Feasibility. https://www.yourdictionary.com/Feasibility Date of access:14 Mar. 2021. 